\title{
The Effect of L2 Writing Ability on L1 Writing Ability
}

\author{
Mahmood Hashemian \\ English Department, Shahrekord University, Shahrekord, Iran \\ Email: m72h@hotmail.com
}

\begin{abstract}
This study was an attempt to examine the effect of $\mathrm{L} 2$ writing ability on $\mathrm{L} 1$ writing ability from a multilingual perspective. To this end, 120 students of Isfahan University, half English majors and half nonEnglish majors, were assigned to 4 groups, consisting of 30 English major senior students, 30 English major freshman students, 30 non-English major senior students and 30 non-English major freshman students (Accounting and Management majors). All the participants were asked to write a paragraph of about 150 words on the topic "What are your plans for the future?" in Farsi. For analyzing the possible syntactic development in each participant's writing ability, 2 measuring criteria were used: 1) Loban Index, and 2) Tunit. To summarize and analyze the data, both descriptive and inferential statistics were utilized. A one-way ANOVA was run to compare the means of the 4 groups on the Loban Index criterion to see whether their differences were statistically significant. In order to observe the real differences of the means of the 4 groups based on the T-unit criterion and also to specify the interaction between the levels of the independent variables, a one-way ANOVA was run. The results of the 4 groups who studied the L2 (i.e., English) with different intensity indicated that the English major senior students outperformed the other 3 groups in the obtained $F$ value on the Loban Index criterion. The findings support the idea that intensive and successful L2 learning can have a beneficial influence on the development of $\mathrm{L1}$ writing ability.
\end{abstract}

Index Terms-multicompetence, interlanguage, writing ability, transfer

\section{INTRODUCTION}

The ability to speak two languages is often seen as something of a remarkable achievement. Because $70 \%$ of the earth's population is thought to be bilingual or multilingual (Choong-Philip, 2006; Trask, 1999), there is good reason to believe that bilingualism is the norm for the majority of people in the world. One of the major issues in the field of second language acquisition research (SLAR) is the role of language learners' L1 in the acquisition of an L2. The concept of transfer in the field of SLAR has been used chiefly in the direction of L1 to L2, but much less is known about the opposite direction (i.e., from L2 to L1) due to the absence of motivation and exposure in an L2 environment.

Cook (1992, p. 580) states that, "the total of multicompetence implies relationships between the two languages stored in the same mind at some level, even if not the merger of holistic competence." Cook (1992, p. 577) asserts that, "the usefulness of the multicompetence idea is that it provides a different perspective from which to look at L2 learning. Instead of L2 users being treated as deficient monolinguals, they should be treated as people in their own right." He has further added that, "clearly, the multicompetence has important consequences for language teacher," in creating L2 competence in their students whether grammatical or communicative. It could further be added that a syllabus that lacks particular attention to the specific nature of L2 users seems inadequate.

Cook (1992) believes that a) bilinguals have a different metalinguistic awareness from people who only know an L1, b) L2 users have different cognitive processes from monolinguals, c) the level of L2 proficiency in academic circumstances is related to the level of L1 proficiency, d) L2 processing cannot be cut off from L1, e) L1 and L2 share the same mental lexicon, f) both L1 and L2 are stored in the same areas of the mind, and finally, g) L2 users differ from monolinguals in the knowledge of L1. The abovementioned evidence is in line with the claim that there seems to be a positive relationship between the knowledge of both L1 and L2, and therefore, the more proficient the L2 learner is in L2 writing ability, the more developed his or her L1 writing ability should be.

Therefore, this study aims at investigating whether L2 writing ability has any influence(s) on L1 writing ability-more specifically, on structural well-formedness and syntactic complication of L1 as the result of Interlanguage development and syntactic growth in an L2. In other words, in the present study, the mutual dependency between L2 and L1 presupposes that conscious mastery of forms and analytic skills developed in L2 learning are likely to support L1 development.

\section{BACKGROUND TO THE STUDY}

The notion of Interlanguage first appeared in the mid 1960s. According to Spolsky (1989), L2 learners' knowledge as a complete whole is quite different from both competing language systems. It is assumed by Selinker (1972) that there exists a latent psychological structure in the brain that is activated whenever an adult attempts to produce meanings in 
the processes of L2 learning. One of the mechanisms assumed to exist in the latent psychological structure is fossilization which includes linguistic items, rules, and subsystems that speakers of a particular L1 will tend to keep in their Interlanguage relative to a particular L2.

Another related notion is multicompetence. According to Cook (1991), multicompetence is the knowledge of two or more languages in a single mind. It is postulated that multicompetence has arisen out of the technical questions of universal grammar (UG) Theory. According to the UG Theory, children cannot induce abstract principles simply from the data presented to them by adults. The theory contends that because the crucial abstract principles of UG are available to children innately, they are able to acquire L1 effortlessly (McLaughlin, 1987). Whereas, Cook (1992) argues that there is an obvious difference between a person who knows an L2 and a person who knows only one language. In other words, people who know two languages may think differently from those who only know one language. Bialystok (1990) argues that as far as grammaticality judgment of semantically anomalous sentences is concerned, bilingual children are better than monolinguals.

Two competing positions are usually distinguished as to the relationship between two language systems in a multicompetent mind. The first one, the separatist position, claims that a multicompetent mind is formed by two or more discrete coexisting language systems without any links between them. Grosjean (1989) has called this view the monolingual view of bilingualism because he believes that this view treats both languages as if they are two L1s. According to the second position, however, the existence of two or more languages in a multicompetent mind has been viewed as a total language system rather then two independent ones. Grosjean (1989) has called this view the holistic position.

One of the factors related to multicommpetence is transfer. Odlin (1989) defines it as "the influence resulting from similarities and differences between the target language and any other language that has been previously (and perhaps imperfectly) acquired." The issue of bidirectionality in transfer is raised by Gundel and Tarone (1992, cited in Gass \& Selinker, 1992). The bidirectional influence forms a unique competence which shows both similarities to and differences from the native monolingual competence (Beare, 2000; Kecskes, 1998).

Cook (1992) claims that learning an L2 might have some effects on L1 knowledge. In the field of phonology, for instance, it has been maintained that the phonological systems of people who know an L2 differs from those of the monolinguals. Cummins (1979) shows how bilinguals often outperform monolinguals. Moreover, Genesee and Stanley (1976) report high correlations between L1 and L2 reading skills and conclude that this proficiency is most likely transferred from one language to the other. Swain and Lapkin (1982) also carried out immersion studies in Toronto and Ottawa. The results of their longitudinal study showed that although immersion students seemed to have lower literacy skills than unilingual students in the first two years, these differences disappeared as soon as English language arts were officially introduced into the curriculum in grade 3. In grade 5, the immersion students even outperformed the Englishonly program students in some aspects. In order to compare the linguistic complexity of L1 and L2, one should appeal to something rather than length, duration, or size. Beaman (1984) determines syntactic complexity of spoken and written discourse by simply comparing the percentage of subordinate clause structures in both discourse types.

There has been a great amount of research about the influence of L1 on L2 (e.g., Cummins, 1991; Harley, 1986; Heidrick, 2006; Mondorf, 2003), but what about the influence that L2 learning might have on L1 literacy skills? This study, therefore, sought answer to the following questions:

1. How does writing ability in L2 learners (in this case, English) affect their L1 (in this case, Persian) writing ability?

2. How does L2 proficiency relate to L1 writing ability?

The findings of this study are probably significant regarding conscious L2 learning in the classroom; they may strengthen the multicompetence view, too. The findings also may enhance multicompetence in the field of L2 and bilingual research and the assumption that the grammar of an L2 in a multicompetent speaker cannot be the same as the equivalent grammar in a monolingual.

\section{METHODOLOGY}

\section{A. Participants}

Four different groups of students of Isfahan University, all Iranian native speakers of Persian with different English proficiency levels, were selected in order to test their L1 writing ability. These four groups had the following characteristics: Group A consisted of 30 English-major seniors; Group B consisted of 30 TEFL freshmen; Group C included 30 non-English-major seniors; and Group D included 30 non-English-major freshmen students of Accounting and Management. All the participants, aged 18-25, were randomly selected from a population of university students.

As the main goal of the study was to investigate the effect of L2 writing competence on L1 writing ability, the abovementioned participants were chosen-those who had developed basic English and those bereft of such knowledge.

\section{B. Materials}

Each participant was asked to write a paragraph of about 150 words in Persian on the topic: "What are your plans for the future?" The reason for selecting this topic was twofold. First, it seemed to be an easy topic, not hampering lowproficiency students. Second, students might often be reluctant to put their thoughts on paper unless a topic awakened their interests. Whereas different topics may have different inducements for people to write, making plans could entice 
them to regulate their writing activities. Therefore, they might use reasoning to form opinions and arguments requiring them to make complex structures.

\section{Procedure}

Each participant was asked to write a paragraph about the abovementioned topic in Persian, and no time limit was imposed on them. After they were finished with their writings, the papers were collected and scored. Each sentence in the written passages was analyzed based on: 1) The Loban index (see the Appendix), which measures subordinate clauses and specifies the complexity of the sentences beginning with subordinate conjunctions like although, nevertheless, consequently, after, etc.; 2) the total number of terminable units for independent clauses and compound sentences. The latter is usually used in order to determine the unity of the passages. Special care was devoted to syntactic structures and T-units because it is assumed that both well-structured sentences and the frequent use of complex sentence structures can be the signs of the development of L1.

Each composition was scored by three qualified Persian raters (university professors) for syntactic complexity based on the abovementioned measurement criteria. In order to make sure that the raters rated the papers homogeneously and they were consistent all throughout their scoring, reliability coefficients were calculated and were found out to be significant for both interrater $(r=.85, p<.05)$ and intrarater $(r=.95, p<.05)$.

\section{DATA ANALYSIS}

In order to find out whether the participants in the four groups differed significantly or not, a one-way ANOVA was conducted. The results are presented in Table 1:

TABLE 1.

THE RESULTS OF THE ONE-WAY ANOVA FOR THE LOBAN INDEX

\begin{tabular}{|l|l|l|l|l|l|}
\hline Source & SS & $\boldsymbol{d} \boldsymbol{\text { MS }}$ & $\boldsymbol{F}$ & $\boldsymbol{P}$ \\
\hline Between Groups & 2.962 & 3 & .987 & 91.759 & .000 \\
\hline Within Groups & 1.248 & 116 & .011 & & \\
\hline Total & 4.210 & 119 & & & \\
\hline
\end{tabular}

The results indicated that the differences were statistically significant $(F=91.759, d f=3, p<.05)$. In order to locate the exact area(s) of difference(s), Scheffe post-hoc test was used. Table 2 shows the results:

TABLE 2.

THE RESUlTS OF THE SCHEFFE POST-HOC TEST

\begin{tabular}{|l|l|l|l|}
\hline Group & Group & Mean Difference & $\boldsymbol{P}$ \\
\hline EMS & EMF & $.14617 * *$ & .000 \\
& NEMS & $.07750^{*}$ & .044 \\
& NEMF & $.41717 * *$ & .000 \\
\hline EMF & EMS & $-.14617 * *$ & .000 \\
& NEMS & -.06867 & .093 \\
& NEMF & $.27100 * *$ & .000 \\
\hline NEMS & EMS & $-.07750^{*}$ & .044 \\
& EMF & .06867 & .093 \\
& NEMF & $.33967 * *$ & .000 \\
\hline NEMF & EMS & $-.41717 * *$ & .000 \\
& EMF & $-.27100 * *$ & .000 \\
& NEMS & $-.33967 * *$ & .000 \\
\hline \multicolumn{4}{|c|}{$*$ Significant at .05 level } \\
\end{tabular}

Following the data presented in Table 2, the following conclusions may be arrived at:

1. The participants in the English-major senior group outperformed the participants in the other three groups.

2. The poorest performance belonged to the participants in the non-English-major freshmen group $(M=.41717)$.

3. The participants in the non-English-major senior group outperformed the non-English-major freshmen group ( $M$ $=.33967)$, but their performance was lower than the English-major senior group $(M=-.07750)$. The performance of the participants in this group and those in the English-major freshmen group was not significantly different $(p>.05)$.

Table 3 presents a one-way ANOVA statistics for the T-unit calculations to find out whether this difference was statistically significant or not:

TABLE 3

THE RESULTS OF THE ONE-WAY ANOVA FOR THE T-UNIT

\begin{tabular}{|l|l|l|l|l|l|}
\hline Source & SS & $\boldsymbol{d}$ & MS & $\boldsymbol{F}$ & $\boldsymbol{P}$ \\
\hline Between Groups & 390.467 & 3 & 130.156 & 27.401 & .000 \\
\hline Within Groups & 551.000 & 116 & 4.750 & & \\
\hline Total & 941.467 & 119 & & & \\
\hline
\end{tabular}


As Table 3 shows, the differences were statistically significant $(F=27.401, d f=3, p<.05)$. In order to find exactly where the difference(s) lay, Scheffe post-hoc test was used. Table 4 shows the results of this test:

TABLE 4.

THE RESUlts OF THE SCHEFFE POST-HOC TEST

\begin{tabular}{|l|l|r|r|}
\hline Group & Group & Mean Difference & \multicolumn{1}{c|}{} \\
\hline EMS & EMF & $3.100^{* *}$ & .000 \\
& NEMS & $1.933^{* *}$ & .010 \\
& NEMF & $4.967 * *$ & .000 \\
\hline EMF & EMS & $-3.100 * *$ & .000 \\
& NEMS & -1.167 & .237 \\
& NEMF & $1.867 *$ & .014 \\
\hline NEMS & EMS & $-1.933^{* *}$ & .010 \\
& EMF & 1.167 & .237 \\
& NEMF & $3.033^{* *}$ & .000 \\
\hline NEMF & EMS & $-4.967 * *$ & .000 \\
& EMF & $-1.867 *$ & .014 \\
& NEMS & $-3.033^{* *}$ & .000 \\
\hline \multicolumn{2}{|c}{$*$ Significant at.05 level. } \\
\end{tabular}

Based on Table 4, the following results could be deduced:

1. The participants in the English-major senior group significantly outperformed the participants in the other 3 groups $(p<.01)$.

2. The poorest performance belonged to the participants in the non-English-major freshmen group $(M=-4.967)$.

3. The participants in the non-English-major senior group outperformed the participants in the non-English-major freshmen group $(M=3.033)$, but their performance was lower than that of the English-major senior group $(M=-1.933)$. The performance of the participants in the non-English-major senior group and those in the English-major freshmen group was not statistically different $(p>.05)$.

\section{DISCUSSION AND CONCLUSION}

This study was an attempt to find out whether L2 writing development may work both ways (i.e., from L1 to L2 and from L2 to L1). In order to find out whether or not writing ability in L1 becomes more sophisticated and develops more intensively for university students, half English majors and half non-English majors, were assigned to the four groups of English-major seniors, English major freshmen, non-English-major seniors, and non-English-major freshmen, each comprising 30 participants. All the participants were asked to write two paragraphs of about 150 words on the topic "What Are Your Plans for the Future?" in Persian. The results of the four groups of the learners who studied L2 with different intensity indicated that the English-major senior students, who were dominantly exposed to the L2 input, outperformed the other three groups.

The findings of this study not only imply conscious L2 learning in classroom but also strengthen the multicompetence view (Cook, 1992), which postulates that "there seems to be strong links between L1 ability and L2 classroom success, even if the results do not generalize for L2 learning outside the classroom" (p. 574). The results of this study might also indicate that if L2 learning is accompanied by intensive formal instruction and adequate motivation, it can have positive effects on the writing ability and syntactic complexity of the L1 of the L2 learners.

The English-major freshmen outperformed the non-English-major freshmen among the four groups. The nonEnglish-major senior group obtained the second highest group mean after the English-major senior group. The results indicate that the non-English-major seniors might have had opportunities to enjoy L2 instruction, but such opportunities had not been intensive enough to exert a qualitative increase in their L1 skills.

These results are also in congruence with those obtained by Caskey-Sirmons and Hickson (1977), who concluded that the meanings of the words in L1 can, to a large extent, be influenced by the L2 words. Similarly, the findings of Kecskes (1998), which were deduced from a longitudinal experiment, demonstrated the positive and beneficial effects of the L2 on the syntactic structures of the L1 in three groups of high school students studying the L2 Russian, French, and English in different classroom settings. It can be further concluded that intensive and successful L2 learning can have a beneficial effect on the development and use of L1 skills.

The results of this study almost demonstrate a qualitative increase in the L1 skills of the English major senior students who are intensively exposed to the L2 instruction for, at least, four years. It can, in fact, be contended that L2 learners may transfer the meaning system they already possess on their own to a new language. In brief, the findings reject the first null hypothesis of the study and validate the following hypothesis: Intensive and successful L2 learning can have a beneficial effect on the development of L1 skills.

It is recommended that L2 teachers take their students' L1 into consideration while teaching the key concepts or when elaborating on grammatical points in the classroom. L2 materials designers should also bear in mind that the users of their materials are not monolinguals but people who are already thinking and using an L2. It can also be claimed that such kind of L2 planning will not come true and bring about changes in the monolingual system unless, as claimed by 
Kecskes (1998, p. 336), "the language learning process is intensive enough and can rely on significant learner motivation."

\section{APPENDIX THE LOBAN INDEX}

$$
L I=\frac{\text { Total number of B, C, D }}{\text { Total number of A, B, C, D }}
$$

Loban's weighted Index of Subordination is based on four categories of subordinate clauses:

- A (1 point): A subordinate clause that is directly dependent upon a main clause.

Example: Although he was new in the city, he managed to get around easily.

- B (2 points): A subordinate clause which modifies or is placed within another subordinate clause.

Example: You should sign up for the trip to Shiraz which is the center of Fars Province that is located in the south of Iran.

- C (2 points): A subordinate clause which contains a verbal construction (i.e., infinitive, gerund, participle).

Example: Since she didn't have time to go to the bookstore before coming to class, she couldn't follow the professor's lecture.

- D (3 points): A subordinate clause which modifies or is placed within another subordinate clause which, in turn, is within or modifying another subordinate clause.

Example: They talked to the teacher who teaches at the school which is on the other side of the town in which Ali was born.

\section{REFERENCES}

[1] Beaman, K. (1984). Coordination and subordination revisited: Syntactic complexity in spoken and written narrative discourse. In D. Tannen, \& R. Freedle (Eds.), Coherence in spoken and written discourse. Norwood: Ablex, 45-80.

[2] Bialystok, E. (1990). Communication strategies. Oxford: Blackwell.

[3] Beare, M. (2000). Writing strategies: Differences in L1 and L2 writing. Retrieved November 10, 2007 from the World Wide Web: www.llas.ac.uk/resources/conferenceitem.aspx?resourceid

[4] Caskey-Sirmons, L. A. \& Hickson, N.P. (1977). Semantic shift and bilingualism: Variation in the color terms of five languages. Anthropological linguistics 19, 358-67.

[5] Choong-Philip, K. (2006). Multicompetence and second language teaching. Retrieved October 15, 2007 from the World Wide Web: www.tc.columbia.edu/academic/tesol/WJFiles/pdf/Choong.pdf

[6] Cook, V. (1991). Chomsky's universal grammar. London: Basil Blackwell, Inc.

[7] Cook, V. (1992). Evidence for multicompetence. Language Learning Journal 42, 557-591.

[8] Cummins, J. (1979). Cognitive/academic language proficiency, linguistic interdependence, the optimum age question and some other matters. Working Papers in Bilingualism 19, 121-129.

[9] Cummins, J. (1991). Interdependence of first and second language proficiency in bilingual children. In E. Bialystok (Ed.), Language processing in bilingual children. Cambridge: CUP, 70-80.

[10] Gass, S. M. \& Selinker, L. (Eds.). (1992). Language transfer and language learning. Rowley, MA: Newbury House.

[11] Genesee, F. \& Stanley, M. H. (1976).The development of English writing skills in French immersion programs. Canadian Journal of Education 1.3,1-17.

[12] Grosjean, F. (1989). Neurolinguists, beware! The bilingual is not two monolinguals in one person. Brain and Language 36.3, $15-25$.

[13] Gundel, J. K. \& Tarone, E. E. (1992). Language transfer and the acquisition of pronominal anaphors. In S. M. Gass \& L. Selinker (Eds.), Language transfer and language learning. Rowley, MA: Newbury House.

[14] Harley, B., Hart, D. \& Lapkin, S. (1986).The effect of early bilingual schooling on first language skills. Applied Psycholinguistics 7, 295-322.

[15] Heidrick, I. (2006). Beyond the L2: How is transfer affected by multilingualism? Retrieved May 8, 2005 from the World Wide Web: www.tc.columbia.edu/academic/tesol/WJFiles/pdf/Heidrick.pdf

[16] Kecskes, I. (1998). The state of L1 knowledge in foreign language learners. Word 49, 321-339.

[17] McLaughlin, B. (1987). Theories of second language learning. London: Edward Arnolds.

[18] Mondorf, B. (2003). Support for more-support. In G. Rohdenburg \& B. Mondorf (Eds.), Determinants of grammatical variation in English. New York: Mouton de Gruyter, 251-304.

[19] Odlin, T. (1989). Language transfer. Cambridge: CUP.

[20] Selinker, L. (1972). Interlanguage. IRAL 10, 209-230.

[21] Spolsky, B. (1989). Conditions for second language learning. Oxford: OUP.

[22] Swain, M. \& Lapkin, S. (1982). Evaluating bilingual education: A Canadian case study. Clevedon, England: Multilingual Matters.

[23] Trask, R. L. (1999). The key concept in language and linguistics. New York: Routledge. 
Mahmood Hashemian is an assistant professor at Shahrekord University. His area of research includes cognitive-semantic linguistics, sociolinguistics, and applied linguistics. He has published articles in academic journals such as IJAL, IJLS, JALS, Linguistik-Online, JLTR, TPLS, Iranian EFL Journal, and International Journal of Social Sciences. Also, he has given lectures in conferences such as TELLSI (4, 7, \& 8), LDP2010, ELT in the Islamic World, and ILC2011, Malaysia. 